Article

\title{
Phytochemical Composition and Antimicrobial Activity of Corydalis solida and Pseudofumaria lutea
}

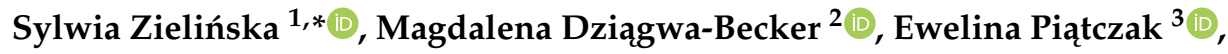 \\ Anna Jezierska-Domaradzka $\left.{ }^{1,4}{ }^{(}\right)$, Malwina Brożyna ${ }^{5}\left(\mathbb{D}\right.$, Adam Junka ${ }^{5}\left({ }^{\circ}\right.$, Mariusz Kucharski $\left.{ }^{2}{ }^{(}\right)$, \\ Serhat Sezai Çiçek ${ }^{6}\left(\mathbb{D}\right.$, Christian Zidorn ${ }^{6}(\mathbb{D})$ and Adam Matkowski ${ }^{1,4}$ (D) \\ 1 Department of Pharmaceutical Biology, Wroclaw Medical University, Borowska 211, 50-556 Wrocław, Poland; \\ anna.jezierska-domaradzka@umed.wroc.pl (A.J.-D.); pharmaceutical.biology@wp.eu (A.M.) \\ 2 Department of Weed Science and Tillage Systems, Institute of Soil Science and Plant, Cultivation State \\ Research Institute, Orzechowa 61, 50-540 Wrocław, Poland; m.dziagwa@iung.wroclaw.pl (M.D.-B.); \\ m.kucharski@iung.wroclaw.pl (M.K.) \\ 3 Department of Biology and Pharmaceutical Botany, Medical University of Łódź, Muszyńskiego 1, \\ 90-151 Łódź, Poland; ewelina.piatczak@umed.lodz.pl \\ 4 Laboratory of Experimental Cultivation, Botanical Garden of Medicinal Plants, Wroclaw Medical University, \\ Al. Jana Kochanowskiego 14, 50-556 Wroclaw, Poland \\ 5 Pharmaceutical Microbiology and Parasitology, Wroclaw Medical University, Borowska 211a, \\ 50-556 Wroclaw, Poland; malwinabrozyna@gmail.com (M.B.); feliks.junka@gmail.com (A.J.) \\ 6 Department of Pharmaceutical Biology, Kiel University, Gutenbergstraße 76, 24118 Kiel, Germany; \\ scicek@pharmazie.uni-kiel.de (S.S.Ç.); czidorn@pharmazie.uni-kiel.de (C.Z.) \\ * Correspondence: sylwia.zielinska@umed.wroc.pl
}

Academic Editors: Francesca Mancianti and Valentina Virginia Ebani Received: 20 July 2020; Accepted: 6 August 2020; Published: 7 August 2020

Abstract: Corydalis and Pseudofumaria are two closely related genera from the Papaveraceae subfamily Fumarioideae with Corydalis solida (C. solida) and Pseudofumaria lutea (P. lutea) as two representative species. Phytochemical analysis revealed significant differences in the quality and quantity of isoquinoline alkaloids, phenolic compounds and non-phenolic carboxylic acids between aerial and underground parts of both species. Using the Liquid chromatography-electrospray ionization-tandem mass spectrometry (LC-ESI-MS/MS) technique, 21 compounds were identified: five protoberberine derivatives, three protopine derivatives, four phenanthridine derivatives, as well as three carboxylic acids, two hydroxycinnamic acids, one chlorogenic acid, one phenolic aldehyde, and two flavonoids. Moroever, significant differences in the content of individual compounds were observed between the two studied species. The phytochemical profile of $C$. solida showed a higher variety of compounds that were present in lower amounts, whereas $P$. lutea extracts contained fewer compounds but in larger quantities. Protopine was one of the most abundant constituents in C. solida (440-1125 $\mu \mathrm{g} / \mathrm{g} \mathrm{d.w.)}$ and in P. lutea (1036-1934 $\mu \mathrm{g} / \mathrm{g}$ d.w.). Moreover, considerable amounts of coptisine $(1526 \mu \mathrm{g} / \mathrm{g})$ and quercetin $(3247 \mu \mathrm{g} / \mathrm{g})$ were detected in the aerial parts of P. lutea. Extracts from aerial and underground parts of both species were also examined for the antimicrobial potential against $S$. aureus, P. aeruginosa and C. albicans. P. lutea herb extract was the most effective (MIC at $0.39 \mathrm{mg} / \mathrm{L}$ ) against all three pathogens.

Keywords: Corydalis solida; Pseudofumaria lutea; protopine; protoberberine derivatives; quercetin

\section{Introduction}

Corydalis DC. is the largest genus in the Fumarioideae subfamily belonging to the Papaveraceae family [1]. It has over 400 species varying in terms of life forms, such as rhizome perennials, early spring geophytes, therophytes and perennial climbing plants [2]. A small genus of Pseudofumaria Medik. 
was separated from the genus Corydalis, based on morphological traits only, e.g., the pistil, which is deciduous and translucent in Pseudofumaria and persistent and green in Corydalis [2,3]. Pseudofumaria comprises only two species: Pseudofumaria lutea (L.) Borkh (syn. Corydalis lutea (L.) DC.) and P. alba (Mill.) Lidén (syn. Corydalis alba (Mill.) Mansf) [3-5].

In Corydalis, several species have been described during the recent few decades rendering a complex and not fully understood taxonomic relationship [6]. However, only some of the species and infraspecific taxa were subjected to phytochemical analysis with over 50 isoquinoline alkaloids listed [7-10]. Yet, the phytochemical relationship to the other taxa within the Fumarioideae subfamily is not fully documented. Therefore, we have chosen two typical and most representative examples of each genus, i.e., Corydalis solida (L.) Clairv and Pseudofumaria lutea to compare their phytochemical profiles.

C. solida is found almost all over Europe, except in the very Northern and Western regions. It is found in the lowlands, foothills and in the low mountain regions as an early spring geophyte associated with European oak-hornbeam forests. It is forming corms, forming small underground bulbs or bulbo-tubers, which unlike a similar species of $C$. cava, are full inside. From the corms grows a single raised stem with two 2- to 3-pinnate leaves and the top racemose inflorescence of purple, monosymmetrical flowers [11]. C. solida is also considered a type species for the genus, originally described as solida subspecies of a basionym Fumaria bulbosa [12,13].

P. lutea grows in Italian and Swiss Alps on shady limestone rocks and screes at an altitude of 500-1700 m a.s.l. As an ornamental plant, it has spread almost all over Europe, and in many countries, including Poland, acquired the status of an established anthropophyte $[3,14,15]$. The place of its occurrence are mostly rocky places and stone walls, always on calcareous soils. P. lutea is a rhizome perennial. Stems is branched, with many 2- to 3-pinnate leaves. The plant produces yellow flowers gathered in racemes. The flowering period is May to October [2].

Data on the traditional or phytomedicinal use of both plants are scarce, which is probably related to the alleged toxicity. C. solida was sometimes used as a calming plant, pain reliever, lowering blood pressure. Starch-rich tubers were cooked and eaten by Slavic peoples and Tatars [16,17]. In Serbia, tubers were used as a sedative, against bleeding, scurvy and worms [18]. Even less data is available for P. lutea. Only one source reports the use of the herb as a gout treatment [19].

Little data on the phytochemical characterization of these two species prompted us to perform comparative analyses. In aerial and underground parts of the plants cultivated in the same location, we analyzed not only alkaloids but also carboxylic acids and various phenolic compounds. The phytochemical analysis was performed using Liquid chromatography-electrospray ionisation-tandem mass spectrometry (LC-ESI-MS/MS) technique.

Insufficient available data on the phytochemistry of these two species prompted us to perform comparative analysis using LC-MS. In the aerial and underground parts of the plants cultivated in the same location, we analyzed not only alkaloids but also carboxylic acids and various phenolic compounds. The phytochemical analyses were set for a better insight into the relationships between the species that were apparently diversified enough, to separate the Pseudofumaria genus from the Corydalis. Changes in the taxonomic position of the species were based on morphological features only, therefore phytochemical characteristics may provide additional valuable information about the closely related and yet different taxa. Moreover, the antimicrobial properties against selected pathogenic bacteria and fungi (P. aeruginosa, S. aureus, C. albicans) as expected from the high alkaloid content, provide a foundation for phytotherapeutic potential of these underutilized herbs.

\section{Results}

\subsection{Qualitative Analysis}

Phytochemical analysis of aerial and underground parts of C. solida and P.lutea revealed two major groups of metabolites in the extracts, benzophenanthridine alkaloids and polyphenolic compounds. A total of 21 compounds were detected-twelve in negative and nine in positive electrospray ionization 
mode. Two protoberberine derivatives: coptisine and berberine, two protopine derivatives: protopine and allocryptopine, and three phenanthridine derivatives: sanguinarine, chelerythrine, and chelidonine, as well as five of their derivatives: a protopine derivative, a coptisine derivative, tetrahydrocoptisine, tetrahydroberberine and a chelidonine derivative were identified. Among the non-alkaloid compounds, there were: three carboxylic acids, two hydroxycinnamic acids, one quinic acid ester, one phenolic aldehyde and two flavonoids (Tables 1 and 2).

The assignment of allocryptopine was based on the parent ion at $m / z 369$ and the product ions at $m / z 352,188,290$. Protopine showed the precursor ion at $m / z 320$, and a putative protopine derivative at $m / z 354$ with product ions at $m / z 320,260,196$. Coptisine gave parent ion at $m / z 320$. Tetrahydrocoptisine and a putative coptisine derivative showed parent ions at $m / z 324$. The assignment of berberine was based on the parent ion at $m / z$ 336. Its derivative-tetrahydroberberine-showed the parent ion at $m / z 340$ and product ions at $m / z 176,149$. The most abundant precursor ions at $m / z 332$ and 348 were assigned for sanguinarine and chelerythrine, respectively. Chelidonine exhibited the parent ion at $\mathrm{m} / \mathrm{z} 370$ and product ions at $\mathrm{m} / \mathrm{z} 356$ and 339 (Tables 1 and 2).

Malic acid presence was based on the parent ion at $m / z 133$, trans-aconitic acid at $m / z 173$, and quinic acid at $m / z$ 191. The assignment of $p$-coumaric acid and trans-caffeic acid was based on the parent ions at $m / z 163$ and 179, respectively. Chlorogenic acid showed the parent ion at $m / z$ 353. The assignment of two flavonoids - rutin and quercetin was based on the presence of parent ions at $m / z 609$ and 301 , respectively. The identification of vanillin was based on the parent ion at $m / z 151$ and quinine sulfate at $m / z 747$ (Tables 1 and 2).

Table 1. The content $(\mu \mathrm{g} / \mathrm{g}$ d.w. $\pm \mathrm{SD})$ of quantitated compounds in aerial parts of C. solida and P. lutea.

\begin{tabular}{|c|c|c|c|c|c|c|}
\hline No & Compound & Parent Ion $(m / z)$ & Product Ion $(m / z)$ & Ion Mode & \multicolumn{2}{|c|}{ Content Mean \pm SD } \\
\hline 1 & protopine derivative & 354 & $320,260,196$ & + & $\mathrm{p}$ & $\mathrm{p}$ \\
\hline 3 & coptisine & 320 & $292,204,262$ & + & $154 \pm 7.42 *$ & $1526 \pm 24.12$ \\
\hline 4 & berberine & 336 & $320,292,321$ & + & $128 \pm 6.79 *$ & $197 \pm 12.10$ \\
\hline 7 & chelerythrine & 348 & $332,304,333$ & + & $18 \pm 1.31$ * & $4 \pm 0.26$ \\
\hline 8 & tetrahydroberberine & 340 & 176,149 & + & $\mathrm{p}$ & $\mathrm{p}$ \\
\hline 9 & tetrahydrocoptisine & 324 & 176,149 & + & $\mathrm{p}$ & $\mathrm{p}$ \\
\hline 10 & coptisine derivative & 324 & 190 & + & $\mathrm{p}$ & $\mathrm{p}$ \\
\hline 11 & sanguinarine & 332 & $274,317,246$ & + & $35 \pm 2.78 *$ & $12 \pm 0.89$ \\
\hline 13 & malic acid & 133 & 115,71 & - & LOQ & LOQ \\
\hline 14 & trans-aconitic acid & 173 & 85,129 & - & LOQ & LOQ \\
\hline 15 & quinic acid & 191 & 85,93 & - & LOQ & LOQ \\
\hline 16 & trans-caffeic acid & 179 & $135,134,89$ & - & $21 \pm 1.52 *$ & $32 \pm 4.90$ \\
\hline 17 & chlorogenic acid & 353 & $191,85,93$ & - & $1 \pm 0.13 *$ & $32 \pm 1.51$ \\
\hline 18 & $p$-coumaric acid & 163 & $119,93,117$ & - & $28 \pm 1.71 *$ & $16 \pm 1.85$ \\
\hline 19 & vanillin & 151 & $136,92,108$ & - & $11 \pm 0.93$ & $13 \pm 1.69$ \\
\hline 20 & quercetin & 301 & $151,65,121$ & - & $177 \pm 9.67 *$ & $3247 \pm 66.43$ \\
\hline 21 & rutin & 609 & 300 & - & LOQ & LOQ \\
\hline
\end{tabular}

p-present, identification was based on mass spectra with no reference substances; nd—not detected; LOD—limit of detection; LOQ - limit of quantification; means marked with an asterisk $\left(^{*}\right)$ within lines differ at significance level $p \leq 0.05$ in a Mann-Whitney $U$ test. 
Table 2. The content ( $\mu \mathrm{g} / \mathrm{g}$ d.w. $\pm \mathrm{SD}$ ) of quantitated compounds in underground parts of $C$. solida and P. lutea.

\begin{tabular}{|c|c|c|c|c|c|c|}
\hline \multirow[t]{2}{*}{ No } & \multirow{2}{*}{$\begin{array}{l}\text { Compound } \\
\text { ALKALOIDS }\end{array}$} & \multirow[t]{2}{*}{ Parent Ion $(m / z)$} & \multirow[t]{2}{*}{ Product Ion $(m / z)$} & \multirow[t]{2}{*}{ Ion Mode } & \multicolumn{2}{|c|}{ Content Mean \pm SD } \\
\hline & & & & & C. solida & P. lutea \\
\hline 1 & protopine derivative & 354 & $320,260,196$ & + & $\mathrm{p}$ & $\mathrm{p}$ \\
\hline 2 & allocryptopine & 369 & $352,188,290$ & + & $516 \pm 21.52 *$ & $6 \pm 1.37$ \\
\hline 3 & coptisine & 320 & $292,204,262$ & + & $233 \pm 5.13 *$ & $307 \pm 17.36$ \\
\hline 4 & berberine & 336 & $320,292,321$ & + & $78 \pm 3.58 *$ & $326 \pm 8.40$ \\
\hline 5 & chelidonine derivative & 370 & 356,339 & + & $\mathrm{p}$ & nd \\
\hline 6 & chelidonine & 354 & $275,189,247$ & + & $1 \pm 0.05$ * & $5 \pm 0.20$ \\
\hline 7 & chelerythrine & 348 & $332,304,333$ & + & $7 \pm 0.37 *$ & $6 \pm 0.12$ \\
\hline 8 & tetrahydroberberine & 340 & 176,149 & + & $\mathrm{p}$ & $\mathrm{p}$ \\
\hline 9 & tetrahydrocoptisine & 324 & 176,149 & + & $\mathrm{p}$ & $\mathrm{p}$ \\
\hline 10 & coptisine derivative & 324 & 190 & + & $\mathrm{p}$ & $\mathrm{p}$ \\
\hline 11 & sanguinarine & 332 & $274,317,246$ & + & $8 \pm 0.28 *$ & $36 \pm 3.53$ \\
\hline 12 & protopine & 320 & $303,107,124$ & + & $1125 \pm 32.63 *$ & $1934 \pm 25.98$ \\
\hline \multicolumn{7}{|c|}{ Other Compounds } \\
\hline 13 & malic acid & 133 & 115,71 & - & LOQ & LOQ \\
\hline 14 & trans-aconitic acid & 173 & 85,129 & - & LOQ & LOQ \\
\hline 15 & quinic acid & 191 & 85,93 & - & LOQ & LOQ \\
\hline 16 & trans-caffeic acid & 179 & $135,134,89$ & - & nd & nd \\
\hline 17 & chlorogenic acid & 353 & $191,85,93$ & - & $6 \pm 1.26 *$ & nd \\
\hline 18 & $p$-coumaric acid & 163 & $119,93,117$ & - & LOD & nd \\
\hline 19 & vanillin & 151 & $136,92,108$ & - & nd & nd \\
\hline 20 & quercetin & 301 & $151,65,121$ & - & $19 \pm 2.88 *$ & $76 \pm 4.64$ \\
\hline 21 & rutin & 609 & 300 & - & nd & nd \\
\hline
\end{tabular}

p-present, identification was based on mass spectra with no reference substances; nd-not detected; LOD—limit of detection; LOQ-limit of quantification; means marked with an asterisk $\left(^{*}\right)$ within lines differ at significance level $p \leq 0.05$ in a Mann-Whitney $U$ test.

\subsection{Quantitative Analysis}

The quantities of most of the detected compounds varied significantly between the species and organs and the proportions between each compound made up markedly different profiles (Figures 1 and 2). Protopine and its derivative were present in aerial and underground parts of both studied species. The content of protopine varied between 440 and $1036 \mu \mathrm{g} / \mathrm{g}$ of dry weight (d.w.) in the aerial parts, and between 1125 and $1934 \mu \mathrm{g} / \mathrm{g}$ d.w. in underground parts of C. solida and P. lutea. Allocryptopine was present in significant concentrations in the herb and corms of C. solida $(328,516 \mu \mathrm{g} / \mathrm{g}$ d.w., respectively), and in low amounts $(6 \mu \mathrm{g} / \mathrm{g}$ d.w.) in the herb and roots of $P$. lutea (Tables 1 and 2$)$. All five protoberberine derivatives were present in aerial and underground parts of the studied species. The coptisine content varied in the range of 307-1526 $\mu \mathrm{g} / \mathrm{g}$ in P. lutea and $154-233 \mu \mathrm{g} / \mathrm{g}$ in C. solida. Berberine amounts varied between 197 and $326 \mu \mathrm{g} / \mathrm{g}$ in P. lutea, and between 128 and $78 \mu \mathrm{g} / \mathrm{g}$ in C. solida. The amounts of phenanthridine derivatives, such as sanguinarine, chelethrine and chelidonine in both species ranged from 1 to $36 \mu \mathrm{g} / \mathrm{g}$ d.w. (Tables 1 and 2).

Ten different polyphenolic compounds were detected in aerial parts and seven in underground parts of C. solida and P. lutea (Tables 1 and 2). Trans-caffeic acid was present only in aerial parts (21-32 $\mu \mathrm{g} / \mathrm{g} \mathrm{d.w.),} \mathrm{and} \mathrm{so} \mathrm{were} p$-coumaric acid (16-28 $\mu \mathrm{g} / \mathrm{g}$ d.w.), vanillin (11-13 $\mu \mathrm{g} / \mathrm{g} \mathrm{d.w.)}$ and rutin (LOQ). Chlorogenic acid (1-32 $\mu \mathrm{g} / \mathrm{g}$ d.w.) and quercetin (19-3247 $\mu \mathrm{g} / \mathrm{g} \mathrm{d.w.)} \mathrm{were} \mathrm{found} \mathrm{in} \mathrm{aerial} \mathrm{and}$ underground parts of both species (Tables 1 and 2). 


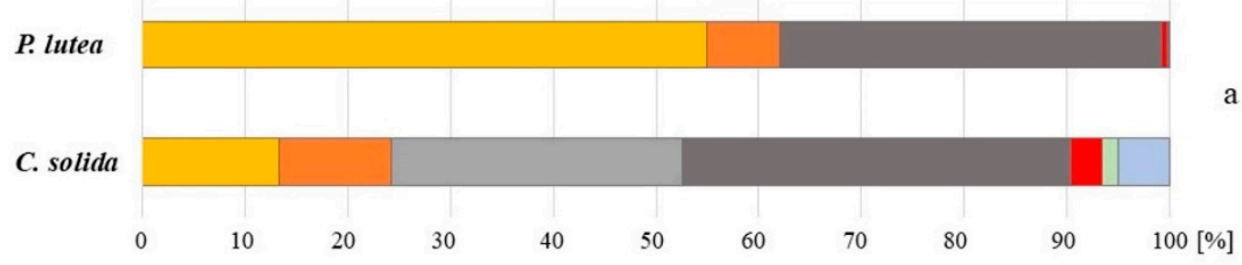

$\square$ coptisine $\square$ berberine $\square$ allocryptopine $\square$ protopine $\square$ sanguinarine $\square$ chelerythrine $\square$ chelidonine

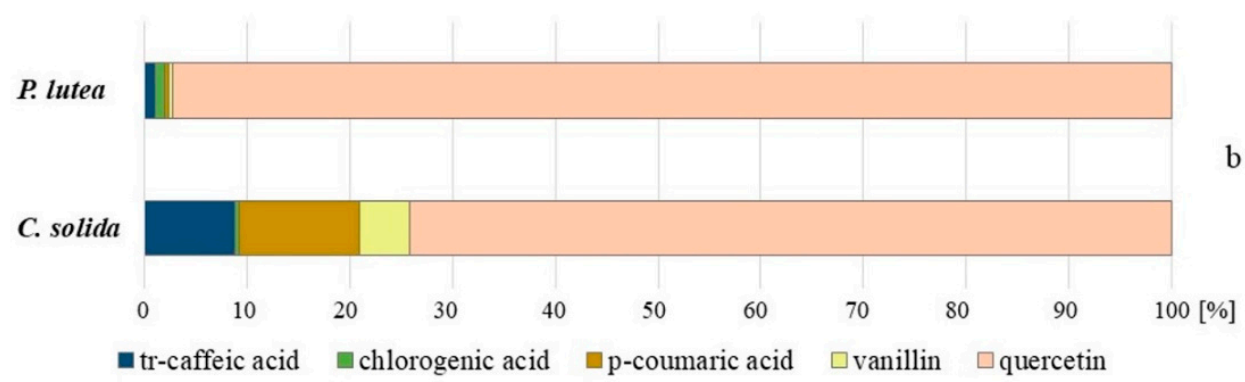

Figure 1. Isoquinoline alkaloids (a) and phenolic compounds (b) proportions in aerial parts of P. lutea and C. solida.

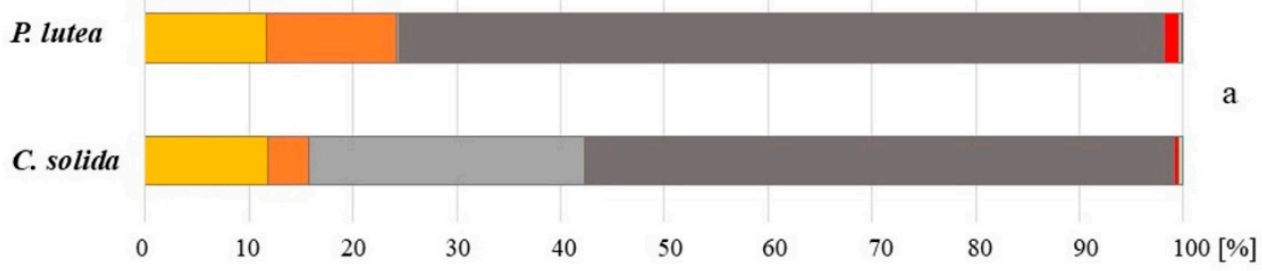

$\square$ coptisine $\square$ berberine $\square$ allocryptopine $\square$ protopine $\square$ sanguinarine $\square$ chelerythrine $\square$ chelidonine

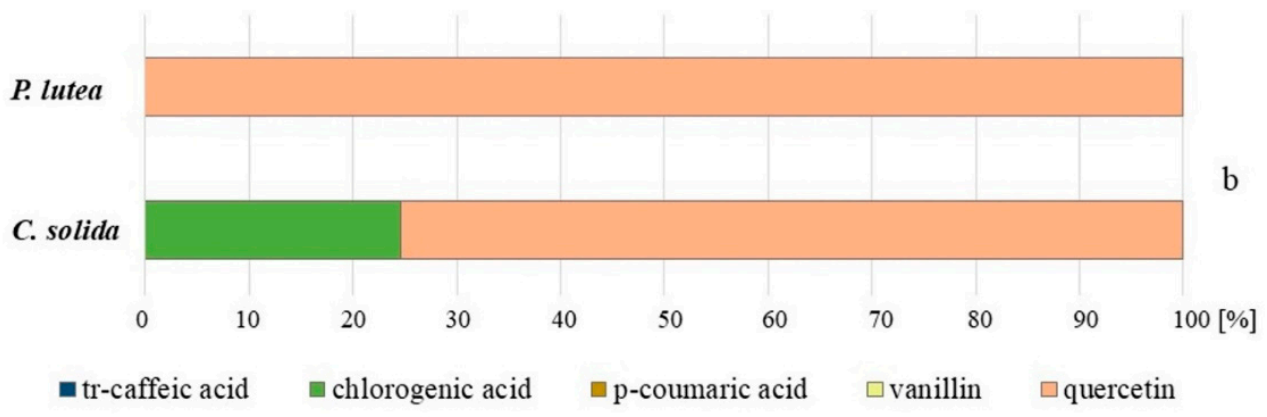

Figure 2. Isoquinoline alkaloids (a) and phenolic compounds (b) proportions in underground parts of P. lutea and C. solida.

\subsection{MIC Evaluation}

To show potential biological applicability of gained extracts (from both aerial and underground parts of both species), we have performed microbiological tests to assess their usefulness in eradication of common nosocomial pathogens (P. aeruginosa, S. aureus, C. albicans).

Extracts of $C$. solida and P. lutea herbs and underground parts were examined for their antimicrobial potential in microtiter-plate based assay against the microbes in a suspension. All of the extracts exhibited strong antimicrobial activity against Gram-positive, Gram-negative bacteria and C. albicans 
yeasts. P. lutea herb extract was the most effective (MIC at $0.39 \mathrm{mg} / \mathrm{L}$ ) against all of the three pathogens (Table 3). Root extract of the species as well as both extracts of $C$. solida exhibited weaker activity against S. aureus (MIC at $1.56 \mathrm{mg} / \mathrm{L}$ ) than against other tested strains (MIC at $0.39 \mathrm{mg} / \mathrm{L}$ ) (Table 3).

Table 3. Minimum Inhibitory Concentration (MIC) $[\mathrm{mg} / \mathrm{L}]$ of water-methanolic extracts from S. solida and P. lutea herb and underground parts.

\begin{tabular}{cccc}
\hline Plant Material & S. aureus & P. aeruginosa & C. albicans \\
\hline C. solida herb & 1.56 & 0.39 & 0.39 \\
C. solida corms & 1.56 & 0.39 & 0.39 \\
P. lutea herb & 0.39 & 0.39 & 0.39 \\
P.lutea roots & 1.56 & 0.39 & 0.39 \\
Octenisept (method suitability control) & 0.0001 & 0.00152 & 0.0001 \\
\hline
\end{tabular}

\section{Discussion}

The chromatographic analysis revealed diverse phytochemical profiles of C. solida and P. lutea. Isoquinoline alkaloids and the non-alkaloid compounds were found in aerial and underground parts of both studied species.

Herb and roots of $P$. lutea contained twice as much protopine as C. solida. Moreover, there was almost ten times more coptisine and almost twenty times more quercetin in the aerial parts of $P$. lutea than in those of C. solida. Additionally, P. lutea roots contained three times more berberine and sanguinarine than corms of $C$. solida (Tables 1 and 2, Figures 1 and 2). Protopine and protoberberine derivatives were previously found in P. lutea along with several other groups such as aporphine and two narceine derivatives. The latter two were soon recognized as artifacts $[9,20]$.

In our research, the amounts of berberine in the herb and roots of P. lutea reached nearly 197 and $326 \mu \mathrm{g} / \mathrm{g}$ d.w., but its presence has not always been found in the previous studies on this species. Preininger et al. in 1978 [10] isolated fourteen different alkaloids from P. lutea among which two protoberberine derivatives - corysamine and palmatine. The identity of the compounds was confirmed by comparing their UV and IR spectra with the reference substances. The authors did not find berberine in their plant material, but they did not specify which plant organs were used. Moreover, no phenanthridine derivatives were detected.

In turn, the herb and corms of $C$. solida were from several dozen to several hundred times richer in allocryptopine than P. lutea (Tables 1 and 2, Figures 1 and 2). Additonally, C. solida herb contained several times more phenanthridine derivatives such as chelidonine, chelerythrine and sanguinarine than the other species (Table 1, Figure 1). Sanguinarine was previously detected in the corms of C. solida by Temizer et al. in 1992 [21]. The authors also found three protoberberine derivatives such as berberine, ophiocarpine and scoulerine, and one alkaloid from another chemical group-protopine. Tubers of C. solida examined by Sturm et al. in 2007 [22] also contained two protoberberine derivatives (corydine, palmatine), and one aporphine derivative bulbocapnine. No protopine and phenanthridine type alkaloids were detected in their plant material [22]. In turn, from the extract of whole C. solida plants, a spirobenzylisoquinoline alkaloid named corysolidine was isolated in 1986 by Rahimizadeh et al. [23]. On the other hand, Kilic et al. in 2019 [24], similarly to our results, found large proportions of protopine in the corms of $C$. solida ssp. incisa. The plant material was collected in Turkey, and five protopine type alkaloids and eight protoberberine type were detected in the extracts. The authors used an advanced LC-QTOF-MS technique for the compounds identification, nevertheless it is difficult to compare their results with ours, because they examined the subspecies of $C$. solida.

Yet in other studies, on another taxon-Corydalis solida subsp. tauricola-a total of 23 alkaloids were isolated from aerial parts, among which no protopine was identified. Twenty-one of them were previously identified (allocryptopine, berberine, ophiocarpine, scoulerine, sinactine, corydalidzine, dehydrocorydaline, sanguinarine, norsanguinarine, bulbocapnine, isoboldine, reticuline, $\alpha$-hydrastine, bicuculline, ochotensine, sibiricine, oxocularine, oxosarcocapnidine, fumariline, cularine), and two 
were new (taurine, tauricoline) [25]. All of these structures can be found in PubChem or ChemSpider databases but tauricoline_-this alklaoid has been only mentioned in the study of Sener et al. (1990) [25]. Some other authors used extracts containing alkaloids but they presented only the TLC chromatogram (visualized in $\mathrm{UV}_{365 \mathrm{~nm}}$ ) of C. solida ssp. slivenensis and C. solida ssp. laxa herbs and tubers [26]. The authors presented their results only without the use of reference substances. Corydalis solida ssp. laxa from Steninge close to Uppsala (Sweden) is probably a hybrid between C. solida and C.pumila as herbarium specimens from 1948 combine the features of both species. It should be noted that C. solida observed on Aland and the Uppland coast, on the eastern coast of Sweden, was also called "laxa", but it presents morphologically diversified characteristics such as ovaries that smoothly attenuate into a short style, lower petals free of gibbosity, and broad leaf lobes [27].

Trying to capture similarity or indicate differences between these taxa, it is also worth paying attention to the phytochemical profile of these species (Figures 1 and 2). Unfortunately, the published data for various taxa, additionally collected from different locations are insufficient. Regarding phytochemical data for C. pumila, one published research study can be found. It has been presented that in corms of C. pumila, several alkaloids such as bulbocapine, corydine, corydaline, palmatine, tetrahydropalmatine were detected [22], but no more detailed phytochemical characteristics are available in the literature. Our results showed that, except quercetin, both plants contained relatively small and comparable amounts of non-phenolic carboxylic acids (malic, trans-aconitic, quinic), hydroxycinnamic acids (trans-caffeic acid and p-coumaric acid), chlorogenic acid, and vanillin in aerial parts (Table 1). The underground parts were even poorer in these metabolites (Table 2, Figures 1 and 2). Conversely, malic acid was previously detected in considerable amounts of $3.9 \mathrm{mg} / \mathrm{g}$ in the herb aqueous extracts of $P$. lutea, and so were (-)-caffeoylmalic acid, p-coumaroylmalic acid, feruloyl-malic acid, caffeic acid, $p$-coumaric acid, ferulic acid, sinapic acid [28].

Since the observations of the morphology and taxonomy of species within the genus Corydalis show many complexities, and there are very few data on the phytochemistry of these plants, we believe that there is a need for comprehensive phytochemical studies of representatives of the current Corydalinae subtribe. Based on our research, further detailed analyses would allow us to determine the proportions between individual compounds, especially these of alkaloid and polyphenol groups contained in many other Corydalis species, and thus select the most valuable raw material. This would be justified because of the wide spectrum of biological activities of both isoquinoline alkaloids and polyphenolic compounds confirmed in the literature, especially antimicrobial [29-35].

From all tested samples, the herb extract of $P$. lutea was the most effective against all three pathogens (MIC at $0.39 \mathrm{mg} / \mathrm{L}$, Table 3). It contained large proportions of coptisine, berberine, protopine and quercetin (Table 1). In our earlier studies, individually tested protopine and coptisine, presented antibacterial properties against $S$. aureus at a concentration of less than $50 \mathrm{mg} / \mathrm{L}$ (73\% CFU reduction), while berberine was less effective (MIC at $125 \mathrm{mg} / \mathrm{L}$ ). Additionally, coptisine showed antibacterial activity against $P$. aeruginosa and C. albicans, similar to allocryptopine (MIC at $>50-125 \mathrm{mg} / \mathrm{L}$ ) [35]. Protopine and protoberberine derivatives such as coptisine and berberine have several pharmacological activities. Beside antimicrobial activity, analgesic, anti-inflammatory, anticancer, antithrombotic, hypoglycaemic, hypolipidaemic, hepatoprotective, and neuroprotective properties were also reported [36-39]. Apart from protoberberine alkaloids, several benzophenanthridine derivatives, such as chelidonine, chelerythrine and sanguinarine were also present in extracts of C. solida and P. lutea. Although these substances were detected in relatively small amounts (from dozen or so to several dozen $\mu \mathrm{g} / \mathrm{g}$ d.w., Tables 1 and 2), they may cause the reinforcement of the antimicrobial properties of extracts. Furthermore, the contribution of polyphenolic constituents in the plant extract, should not be neglected. This class of compounds may be strongly involved in the microbes eradication [40]. In one of the most recent studies on polyphenolic compounds contained in extracts of Anthemis praecox aerial parts, quercetin rich extracts presented antimicrobial activity, although stronger against Gram-positive than Gram-negative bacteria [41]. It should be noted that a general trend in antimicrobial activity presented in Table 3 indicates higher efficiency of tested extracts against P. aeruginosa and C. albicans than against 
S. aureus. In the studies of Orhan et al. (2006) [42], a large number of alkaloids that were isolated from several Corydalis and Fumaria species, were also more active against Gram-negative than Gram-positive bacteria. P. aeruginosa is closely related with Pseudomonas putida, a microbial cohabitant of C. solida and $P$. lutea environment and growth-promoting rhizobacteria. Several deadly plant pathogen strains belong to Pseudomonas syringae. Yeast-like fungi, to whom C. albicans belongs to, can colonize, co-exist or cause diseases in a vast variety of plant species. In turn, S. aureus, is a highly-specialized opportunistic pathogen of animal and men. One may thus assume that observed higher potential of analyzed plants to eradicate $C$. albicans and P. aeruginosa than $S$. aureus may be related to the ability of analyzed plants to combat microorganisms which exist in plants' habitat in order to avoid the negative impact of microbial overgrowth [43-46]. This hypothesis, along with the presented data on the higher antimicrobial efficacy of plant extracts versus individually tested alkaloids, indicates the necessity of further detailed phytochemical and bioactivity investigations. The complex analysis would allow to set down new plant-derived products of desired medicinal properties.

\section{Material and Methods}

\subsection{Plant Material}

Whole plants of C. solida and P. lutea were collected from Botanical Garden of Maria Curie-Skłodowska University in Lublin on 20th of April 2018. C. solida was replanted from Stone pit of Kazimierz Dolny, Poland in 1976, P. lutea was replanted from the garden of a private person from Świdnik, Poland in 2006, and from that time both species are in the collection of Botanical Garden of Maria Curie-Skłodowska University in Lublin (Geographical location: $51^{\circ} 6^{\prime} \mathrm{N}, 22^{\circ} 30^{\prime} \mathrm{E}, 200 \mathrm{~m}$ a.s.l.), under the codes: 1910P, 4223A, respectively. Plants grew on loess soils without additional treatments such as fertilization. C. solida grew in a shadowed place, P. lutea grew in an exposed, sunny location. The average temperature in April 2018 was $14.2{ }^{\circ} \mathrm{C}$ and precipitation was $36.5 \mathrm{~mm}$ (data from the official report of the Meteorological Observatory of the Meteorology and Climatology Department, the Maria Curie-Skłodowska University in Lublin). Continental influences with large amplitudes of annual temperatures, a long summer and a long cool winter predominate in the Lublin Upland. During the years 1951-2010 average annual perennial temperature was $+8.3^{\circ} \mathrm{C}$, and average annual multi-annual precipitation was $550.6 \mathrm{~mm}$.

Plants were collected, dried in a heated herbal drier at $25^{\circ} \mathrm{C}$ for $72 \mathrm{~h}$ and separated into aerial and underground parts. In case of $C$. solida there were corms, and in case of $P$. lutea-roots.

\section{Plant Material Extraction}

Ten individual plants of each species were used for extraction. Three independent experimental repetitions were performed followed by two analytical repetitions. Dried plant material was ground to powder using mortar and pestle and extracted with $80 \%$ methanol acidified with $0.1 \%$ formic acid $(v / v)$ in the ultrasonic bath (IS-20, Intersonic, Olsztyn, Poland) twice for $30 \mathrm{~min}$. The extracts were prepared in a solvent-to-solid ratio 1:20 (v:w) according to the procedure performed in our previous studies [47]. The content of compounds was expressed in micrograms per $\mathrm{g}$ of dry weight $[\mu \mathrm{g} / \mathrm{g}$ d.w.].

\subsection{Phytochemical Analysis}

The isoquinoline alkaloids and phenolic compounds identification and quantification of C. solida and P. lutea were performed using liquid chromatography equipped with electrospray ionization-tandem mass spectrometry with a triple quadrupole analyzer.

Reference substances such as protopine, berberine, sanguinarine, chelidonine, chelerythrine were purchased from Extrasynthese (Genay, France); allocryptopine, coptisine, malic acid, $t$-aconitic acid, quinic acid, caffeic acid, chlorogenic acid, p-coumaric acid, vanillin, rutin, and quercetin were purchased from Sigma-Aldrich (St. Louis, MO, USA). 


\subsubsection{Liquid Chromatography Mass Spectrometry}

The analyzes were conducted using a Shimadzu Prominence UFLC system (Shimadzu, Kyoto, Japan). LC system was equipped with a binary solvent manager-LC-30 ADXR; a degasser-DGU-20A3; a column oven-CTO-10ASVP; an autosampler-SIL 20AXR; a system controller-CBM-20A. For compound separation, Kinetex column C18, $2.6 \mu \mathrm{m}$ particle size, $100 \times 3.0 \mathrm{~mm}$ (Phenomenex, Torrance, CA, USA) was used at a flow rate of $0.40 \mathrm{~mL} \mathrm{~min}^{-1}$. The mobile phase consisted of a mixture A-B composed of $10 \mathrm{mM}$ ammonium formate in water (A) and $0.1 \%$ formic acid in methanol (B). The methanol percentage was changed linearly as follows: $0 \mathrm{~min}, 10 \% ; 10 \mathrm{~min}, 85 \% ; 13 \mathrm{~min}, 85 \%$; $16 \mathrm{~min}, 10 \%$. Sample volume injection was $10 \mathrm{~mL}$. Tandem mass spectrometer-LCMS-8030 (Shimadzu, Kyoto, Japan)—with a triple quadrupole mass spectrometer equipped with ESI source cooperating in both positive and negative ionization modes was used. LabSolution Ver. 5.6 (Shimadzu, Kyoto, Japan) software was used for quantitative data processing.

\subsubsection{Identification and Quantification}

The multiple reaction monitoring (MRM) mode was used for identification and quantification of alkaloids and the remaining compounds. The identification was based on the retention time compared with the corresponding standards together with the ion intensity ratio of the chosen parent ion $(\mathrm{Q})$, product ion $(\mathrm{q})$ and previously identified compounds reported in the literature [48]. The limit of detection (LOD) was calculated according to a signal-to-noise ratio $(\mathrm{S} / \mathrm{N})$ of 3 and the limit of quantitation (LOQ) to $\mathrm{S} / \mathrm{N}$ ratio of 10 . The linearity of the method was studied for all of the chosen compounds based on five concentration points assessed in triplicate. The square correlation coefficient (r2) $\geq 0.99$ was achieved for most of the compounds, or was very close. Quantitation was based on external standardization.

\subsection{Experimental Design for Bioactivity Assays}

In order to determine the antimicrobial activity of the tested substances, MIC (Minimum Inhibitory Concentration) assessment was conducted in 96-well titration micro-plates. Three reference strains were analyzed: Staphylococcus aureus ATCC 6538, Pseudomonas aeruginosa ATCC 15442, Candida albicans ATCC 1032 (obtained from ATCC, Manasas, VA, USA). Initially, the $0.5 \mathrm{McF}$ arland (MF) density of the tested strain's suspension in Tryptic Soya Broth (TSB) medium was prepared and diluted to $10^{5}$ Colony-Forming Units (CFU)/mL. Next, $100 \mu \mathrm{L}$ of TSB medium was poured into the wells of the plate. Subsequently, $100 \mu \mathrm{L}$ of the methanolic extract was added to the first well. Then, $100 \mu \mathrm{L}$ of this solution (consisting of a mixture of methanolic extract and TSB) was transferred to the next well of 96-well plate. This operation was repeated 9 times. Finally, every of 10 wells of 96 -well plate in a row, was filled with $100 \mu \mathrm{L}$ of a solution containing decreasing concentrations of analyzed extracts. Next, $100 \mu \mathrm{L}$ of bacterial/fungal suspension ( $105 \mathrm{cfu} / \mathrm{mL})$ was added to each well. The final volume of $200 \mu \mathrm{L}$ was obtained for each well. The plate was incubated at $37^{\circ} \mathrm{C}$ and shaken $(400 \mathrm{rpm} / \mathrm{min}$.) for $24 \mathrm{~h}$. Control of microorganisms' growth (the culture without any of plant extracts) and control of sterility (medium only) were also performed. Moreover, antimicrobial activity of $100 \%$ methanol, $0.1 \%$ solution of formic acid, mixture of $100 \%$ methanol and $0.1 \%$ formic acid (4:0.5 ratio) and Octenisept (Schülke, Norderstedt, Germany) - clinically used antiseptic product of confirmed antimicrobial activity was examined as the positive control. After incubation, $20 \mu \mathrm{L}$ of $1 \%$ solution of triphenyl tetrazolium chloride, TTC (Sigma-Aldrich, München, Germany) was introduced to the wells and incubated for $2 \mathrm{~h} / 37^{\circ} \mathrm{C}$. A change of TTC to red formazan indicated the presence of metabolically active microorganisms. The MIC value was determined as the first colourless well, next to the red well.

\subsection{Statistical Evaluation}

Presented data of alkaloids and phenolic compounds content are mean values from 6 independent extractions \pm standard deviation (SD). Statistical significance of the quantitative differences between 
extracts was estimated by one-way ANOVA with nonparametric Mann-Whitney $U$ test at significance level $p \leq 0.05$. All analyses were conducted using Statistica 13.1PL (StatSoft, Krakow, Poland, 2016).

\section{Conclusions}

The above data indicate the existence of much controversy regarding the types and number of alkaloids present in C. solida and P. lutea. It should be noted that there are relatively few studies on the phytochemical characterization of both species. Many of them were published in the seventies and nineties of the last century. Since then, analytical techniques have undergone enormous progress, leading to reduced measurement times and increased precision. Based on this, to make a broad picture of the phytochemical profiles of plants belonging to Corydalis genus, it would be necessary to examine the aerial and underground parts of multiple Corydalis species and related taxa, collected from different locations and different vegetation periods. Well-characterized plant material can stand a chance of applying it against clinical strains of pathogenic bacteria and fungi.

Author Contributions: conceptualization, S.Z.; methodology, S.Z., A.J., C.Z., S.S.Ç. and M.D.-B.; data curation, S.Z., A.J. and M.D.-B.; software, S.Z., S.S.Ç., A.J. and M.D.-B.; validation, M.D.-B. and E.P.; formal analysis, S.Z., S.S.Ç., M.B. and M.D.-B.; investigation, S.Z.; resources, A.M., M.K.; writing-original draft preparation, S.Z.; writing—review and editing, S.Z., A.J.-D., A.J., E.P., S.S.Ç., C.Z., A.M.; visualization, S.Z.; supervision, A.M., C.Z., and S.S.Ç.; project administration, S.Z.; funding acquisition, A.M. All authors have read and agreed to the published version of the manuscript.

Funding: This study was conducted within the research project "Biotic and abiotic stress elicitors as modulators of isoquinoline alkaloid profile towards specific antimicrobial properties of medicinal plants from the Papaveraceae" funded by the National Science Centre Poland (NCN) Sonata 15 no 2019/35/D/NZ7/00266 and partly supported by the young researcher grant: STMD230.20.126 from Wroclaw Medical University and the Wroclaw Medical University Foundation (Fundacja Uniwersytetu Medycznego we Wrocławiu, FUM). Preparing and editing of the manuscript for publication was supported by Wroclaw Medical University funds: SUB.D230.20.002 and SUB.D033.19.009. The Botanical Garden of Medicinal Plants receives support for a special research facility from the Ministry of Science and Higher Education (MNiSW), Republic of Poland, decision No. 96/E394/SPUB/SP/2019. The authors give a special appreciation to Grażyna Szymczak, Director of the Botanic Garden of Maria Curie-Skłodowska University at Lublin for providing the plants and Ms. Hanna Zielinska for her assistance in preparing the graphic.

Conflicts of Interest: The authors declare no conflict of interest.

\section{References}

1. Stevens, P.F. Angiosperm Phylogeny Website, Version 14. Available online: http://www.mobot.org/MOBOT/ research/APweb/ (accessed on 13 January 2020).

2. Lidén, M. Fumariaceae. In Flowering Plants Dicotyledons. The Families and Genera of Vascular Plants; Kubitzki, K., Rohwer, J.G., Bittrich, V., Eds.; Springer: Berlin/Heidelberg, Germany, 1993.

3. Euro + Med PlantBase-The Information Resource for Euro-Mediterranean Plant Diversity. Available online: http://ww2.bgbm.org/EuroPlusMed/PTaxonDetail.asp?NameId=93318\&PTRefFk=7500000/ (accessed on 20 January 2020).

4. POWO. Plants of the World Online.Facilitated by the Royal Botanic Gardens, Kew. 2019. Available online: http://www.plantsoftheworldonline.org/ (accessed on 13 January 2020).

5. USDA, Agricultural Research Service, National Plant Germplasm System. Germplasm Resources Information Network (GRIN-Taxonomy). National Germplasm Resources Laboratory, Beltsville, Maryland. Available online: https://npgsweb.ars-grin.gov/gringlobal/taxonomydetail.aspx?id=405102/ (accessed on 21 January 2020).

6. Lidén, M. Proposal to change the typification of Corydalis, nomen conservandum. Taxon 1981, 30, $322-325$. [CrossRef]

7. Salacova, K. Biological Activity of Plant Metabolites XII. Alkaloids of the Genus Corydalis DC. (Fumariaceae) and Their Biological Activity. Ph.D. Thesis, Charles University, Faculty of Pharmacy at Hradec Kralove, Hradec Králové, Czech Republic, 2009.

8. Meyer, A.; Imming, P. R(-)-Canadaline as first secoberbine alkaloid from Corydalis cava. Phytochem. Lett. 2008, $1,168-170$. 
9. Preininger, V.; Novak, J.; Simanek, V.; Santavg, F. Isolation and chemistry of the alkaloids from plants of the papaveraceae. LXXIII. Planta Med. 1978, 33, 396-402.

10. Preininger, V.; Dolejs, L.; Smysl, B.; Simanek, V. Isolation and chemistry of alkaloids from plants of the papaveraceae. LXXV. Planta Med. 1979, 36, 213-218.

11. Zarzycki, K.; Trzcińska-Tacik, H.; Różański, W.; Szelag, Z.; Wołek, J.; Korzeniak, U. Ecological Indicator Values of Vascular Plants of Poland; Polish Academy of Sciences: Kraków, Poland, 2002.

12. Greuter, W. Proposal to reject Fumaria bulbosa L. Taxon 1987, 36, 169-173. [CrossRef]

13. Brummitt, R.K. Report of the committee for spermatophyta: 28. Taxon 1984, 33, 705-707. [CrossRef]

14. Mirek, Z.; Piękoś-Mirkowa, H.; Zając, A.; Zając, M. Flowering Plants and Pteridophytes of Poland. A Checklist; Szafer Institute of Botany, Polish Academy of Sciences: Kraków, Poland, 2002; p. 442.

15. Tokarska-Guzik, B.; Dajdok, Z.; Zając, M.; Zając, A.; Urbisz, A.; Danielewicz, W.; Hołdyński, C.Z. Rośliny Obcego Pochodzenia w Polsce ze Szczególnym Uwzzlędnieniem Gatunków Inwazyjnych, Wyd; Generalna Dyrekcja Ochrony Środowiska: Warszawa, Poland, 2014.

16. Łuczaj, Ł. Dzikie Rośliny Jadalne Polski; Wydawnictwo Chemigrafia: Krosno, Poland, 2002; p. 86.

17. Moszyński, K. Kultura Ludowa Stowian, (cz.1); Polska Akademia Umiejętności: Kraków, Poland, $1929 ;$ p. 18.

18. Popović, Z.; Smiljanić, M.; Matić, R.; Kostić, R.; Nikić, P.; Bojović, S. Phytotherapeutical plants from the Deliblato Sands (Serbia): Traditional pharmacopoeia and implications for conservation. Indian J. Tradit. Knowl. 2012, 11, 385-400.

19. Boegge, S.; Kesper, S.; Verspohl, E.J.; Nahrstedt, A. Reduction of ACh-induced contraction of rat isolated ileum by coptisine, (+)-caffeoylmalic acid, Chelidonium majus, and Corydalis lutea extracts. Planta Med. 1996, 62, 173-174.

20. Manske, R.H.F. The alkaloids of Fumariaceous plants XXR. Corydalrs lutea (L.) DC. Can. J. Res. 1939, $17 B, 51$.

21. Temizer, H.; Sener, B.; Temizer, A.; Kir, S. Determination of alkaloids by differential pulse polarography. III Corydalis alkaloids. Electroanal 1992, 4, 737-740.

22. Sturm, S.; Seger, C.; Godejohann, M.; Spraul, M.; Stuppner, H. Conventional sample enrichment strategies combined with high-performance liquid chromatography-solid phase extraction-nuclear magnetic resonance analysis allows analyte identification from a single minuscule Corydalis solida plant tuber. J. Chromatogr. A 2007, 1163, 138-144.

23. Rahimizadeh, M.; Miller, R.R.; Onur, M.A.; Gozler, T.; Shamma, M. (+)-corysolidine, a spirobenzylisoquinoline alkaloid from Corydalis solida. Phytochemistry 1986, 25, 2245-2246.

24. Kilic, K.M.; Kaya, E.; Aysal, A.I.; Sener, B. Evaluation of some biological activities of the tubers of Corydalis solida (L.) Clairv. ssp. incisa Lieden growing in Turkey. S. Afr. J. Bot. 2019, 127, 195-200.

25. Sener, B.; Temizer, H. Chemical studies on the alkaloids from Corydalis solida subsp. tauricola. Planta. Med. 1990, 56, 510 .

26. Adsersen, A.; Gauguin, B.; Gudiksen, L.; Jager, A.K. Screening of plants used in Danish folk medicine to treat memorydisfunction for acetylcholinesterase inhibitory activity. J. Ethnopharmacol. 2006, 104, 418-422.

27. Lidén, M. Notes on Corydalis sect. Corydalis in the Baltic area. Nord. J. Bot. 1991, 11, 129-133.

28. Boegge, S.C.; Nahrstedt, A.; Linscheid, M.; Nigge, W. Distribution and stereochemistry of hydroxycinnamoylmalic acids and of free malic acids in Papaveraceae and Fumariaceae. Z. Naturforsch. 1995, 50c, 608-615.

29. Bravo, A.; Anacona, J.R. Metal complexes of the flavonoid quercetin: Antibacterial properties. Transit. Met. Chem. 2001, 26, 20-23.

30. Boots, A.W.; Li, H.; Schins, R.P.F.; Duffin, R.; Heemskerk, J.W.M.; Bast, A.; Haenen, G.R.M.M. The quercetin paradox. Toxicol. Appl. Pharm. 2007, 222, 89-96.

31. Gorlenko, C.L.; Kiselev, H.Y.; Budanova, E.V.; Zamyatnin, A.A., Jr.; Ikryannikova, L.N. Plant secondary metabolites in the battle of drugs and drug-resistant bacteria: New heroes or worse clones of antibiotics? Antibiotics 2020, 9, 170.

32. Pal, A.; Tripathi, A. Demonstration of bactericidal and synergistic activity of quercetin with meropenem among pathogenic carbapenem resistant Escherichia coli and Klebsiella pneumoniae. Microb. Pathog. 2020, 143,104120 .

33. Sholkamy, E.N.; Ahmed, M.S.; Yasser, M.M.; Mostafa, A.A. Antimicrobial quercetin 3-O-glucoside derivative isolated from Streptomyces antibioticus strain ess_amA8. J. King Saud Univ. Sci. 2020, 32, 1838-1844.

34. Zhang, L.-L.; Zhang, L.-F.; Xu, J.-G. Chemical composition, antibacterial activity and action mechanism of diferent extracts from hawthorn (Crataegus pinnatifda Bge.). Sci. Rep. UK 2020, 10, 8876. 
35. Zielińska, S.; Wójciak-Kosior, M.; Dziągwa-Becker, M.; Gleńsk, M.; Sowa, I.; Fijałkowski, K.; Rurańska-Smutnicka, D.; Matkowski, A.; Junka, A. The activity of isoquinoline alkaloids and extracts from Chelidonium majus against pathogenic bacteria and candida sp. Toxins 2019, 11, 406.

36. Kedzia, B.; Hołderna-Kedzia, E. The effect of alkaloids and other groups of plant compounds on bacteria and fungi. Postep. Fitoter. 2013, 1, 8-16.

37. Zhang, C.; Sheng, J.; Li, G.; Zhao, L.; Wang, Y.; Yang, W.; Yao, X.; Sun, L.; Zhang, Z.; Cui, R. Effect of berberine and its derivatives on cancer: A system pharmacology review. Front. Pharmacol. 2020, 10, 1461.

38. Guo, J.; Wang, S.B.; Yuan, T.Y.; Wu, Y.J.; Yan, Y.; Li, L.; Xu, X.N.; Gong, L.I.; Qin, H.I.; Fang, L.H.; et al. Coptisine protects rat heart against myocardial ischemia/reperfusion injury by suppressing myocardial apoptosis and inflammation. Atherosclerosis 2013, 231, 384-391.

39. Saeed, S.A.; Gilani, A.H.; Majoo, R.U.; Shah, B.H. Anti-thrombotic and anti-inflammatory activities of protopine. Pharmacol. Res. 1997, 36, 1-7.

40. Kikowska, M.; Derda, M.; Thiem, B.; Włodarczyk, A.; Długaszewska, J.; Stochmal, A.; Żuchowski, J.; Hadaś, E. Evaluation of antiamoebic and antimicrobial activities in vitro of Chaenomeles japonica (Thunb.) lindl. ex spach extracts. Acta Biol. Cracs. Bot. 2019, 61, 47-58. [CrossRef]

41. Belhaoues, S.; Amri, S.; Bensouilah, M. Major phenolic compounds, antioxidant and antibacterial activities of Anthemis praecox Link aerial parts. S. Afr. J. Bot. 2020, 131, 200-205.

42. Orhan, I.; Özcelik, B.; Karaoglu, T.; Sener, B. Antiviral and antimicrobial profiles of selected isoquinoline alkaloids from Fumaria and Corydalis species. Z. Naturforsch. 2007, 62c, 19-26.

43. Mergaert, P. Role of antimicrobial peptides in controlling symbiotic bacterial populations. Nat. Prod. Rep. 2018, 35, 336.

44. Geddes, B.A.; Paramasivan, P.; Joffrin, A.; Thompson, A.L.; Christensen, K.; Jorrin, B.; Brett, P.; Conway, S.J.; Oldroyd, E.D.; Poole, P.S. Engineering transkingdom signaling in plants to control gene expression in rhizosphere bacteria. Nat. Commun. 2019, 10, 3430.

45. Khan, M.S.A.; Zahin, M.; Hasan, S.; Husian, F.M.; Ahmad, I. Inhibition of quorum sensing regulating bacterial functions by plant essential oils with special reference to clove oil. Lett. Appl. Microbiol. 2009, 49, 354-360.

46. Manefield, M.; de Nys, R.; Naresh, K.; Read, R.; Givskov, M.; Steinberg, P.; Kjelleberg, S. Evidence that halogenated furanones from Delisea pulchra inhibit acylated homoserine lactone (AHL)-mediated gene expression by displacing the AHL signal from its receptor protein. Micro. Soc. 1999, 145, 283-291.

47. Sowa, I.; Zielinska, S.; Sawicki, J.; Bogucka-Kocka, A.; Staniak, M.; Bartusiak-Szczesniak, E.; Podolska-Fajks, M.; Kocjan, R.; Wojciak-Kosior, M. Systematic evaluation of chromatographic parameters for isoquinoline alkaloids on XB-C18 core shell column using different mobile phase compositions. J. Anal. Methods Chem. 2018, 3, 1-8.

48. Grosso, F.; Ferreres, Gil-Izquierdo, A.; Valentão, P.; Sampaio, M.; Lima, J.; Andrade, P.B. Box-Behnken factorial design to obtain a phenolic-rich extract from the aerial parts of Chelidonium majus L. Talanta 2014, $130,128-136$.

Sample Availability: Samples of the plant material and test extracts are available from the authors.

(C) 2020 by the authors. Licensee MDPI, Basel, Switzerland. This article is an open access article distributed under the terms and conditions of the Creative Commons Attribution (CC BY) license (http://creativecommons.org/licenses/by/4.0/). 